\title{
Effects of pyrroloquinoline quinone and vitamin C on diabetes associated cardiac oxidative damages and hyperlipidemia in mice: biochemical and histopathological study
}

\begin{abstract}
Enhanced hyperglycemia is associated with oxidative stress and hyperlipidemia that is also responsible for an increased risk factor for diabetes associated cardiovascular problems. As pyrroloquinoline quinone (PQQ) is a known antioxidative agent, the primary aim of this study was to explore the hitherto unknown potential of PQQ in regulating STZ-induced oxidative damages in heart and associated cardiovascular problems. Healthy male mice were divided into seven groups such as normoglycemic; PQQ treated control; STZ-treated $(150 \mathrm{mg} / \mathrm{kg})$; STZ+PQQ treated $(5,10$ and $20 \mathrm{mg}$ / $\mathrm{kg}$, respectively); and STZ+Vit. C treated $(50 \mathrm{mg} / \mathrm{kg}$ ). At the end of the experiment( after 15 days of treatment), animals were sacrificed and markers of oxidative stress, various antioxidants, lipid profiles, alterations in insulin, lactate dehydrogenase $(\mathrm{LDH})$, relative risk value (RR-value), atherogenic index (AI) and cardiac tissue histology were evaluated. STZ - treated animals not only developed oxidative stress as indicated by an increase in lipid peroxidation (LPO), lipid hydroperoxide (LOOH), $\mathrm{LDH}, \mathrm{RR}-\mathrm{value}$ and AI but also by a decrease in the levels of insulin, high density lipoprotein (HDL-C), superoxide dismutase, catalase, glutathione peroxidase and reduced glutathione. Following the administration of PQQ, particularly at $20 \mathrm{mg} / \mathrm{kg}$ in diabetic animals, all these adverse effects were ameliorated with a decrease in LPO, $\mathrm{LOOH}, \mathrm{LDH}$ and different lipids; with a parallel increase in cellular antioxidants, HDL $-\mathrm{C}$ and insulin level, suggesting cardioprotective effects of the test drug. Better effects were observed, as compared to that of Vit. C. Our study reveals that PQQ may have better ameliorating potential than Vit. $\mathrm{C}$ in regulation of the cardiovascular problems in diabetic patients.
\end{abstract}

Keywords: diabetes mellitus, pyrroloquinoline quinine, vitamin-C, heart, lactate dehydrogenase, insulin, antioxidative agents
Volume 4 Issue I - 2017

Narendra Kumar, Anand Kar
School of Life Sciences, Devi Ahilya University, India

Correspondence: Narendra Kumar, School of Life Sciences, Devi Ahilya University, Takshashila Campus, Khandwa Road, Indore- 452017, M.P., India, Tel +919-425-48I-242, Fax +917-312-360-026, Email narendrakumar93@gmail.com

Received: August 19, 2017 | Published: October 23, 2017
Abbreviations: DM, diabetes mellitus; CVDs, cardiovascular diseases; PQQ, pyrroloquinoline quinone; LDH, lactate dehydrogenase; RR-value, relative risk value; LPO, lipid peroxidation; $\mathrm{LOOH}$, lipid hydroperoxide; HDL-C, high density lipoprotein; ROS, reactive oxygen species; MDA, malondialdehyde; STZ, streptozotocin; PBS, phosphate buffered saline; BSA, bovine serum albumin; FR, free-radical; PPAR, peroxisome proliferator-activated receptor

\section{Introduction}

Incidence of diabetes mellitus (DM) and associated cardiovascular diseases (CVDs) have increased worldwide in recent years. Approximately $80 \%$ of total deaths are thought to occur among the CVDs patients. ${ }^{1,2}$ Untreated diabetes usually develops CVDs such as coronary heart disease, peripheral arterial disease, hypertension, stroke and cardiomyopathy. ${ }^{3}$ In diabetes, the circulating free radicals contribute to the progression of heart disease and possibly mediate the process of apoptosis, a state in which increased oxidative stress is observed. ${ }^{4}$ An earlier report suggests that high glucose concentration promotes apoptosis in vitro; suggesting that hyperglycemia in diabetes has the potential to cause cellular damage. ${ }^{5}$ Very often, increased oxidative stress in diabetes is believed to be the result of increased production of reactive oxygen species (ROS) and decreased antioxidant defence system. ${ }^{6}$ In fact, lipid peroxidation results in malondialdehyde (MDA) formation as a cytotoxic product via membrane disruption and finally leads to cell damage and necrosis. As incidence of CVDs is pretty high in diabetic patients, the identification of new pharmacological agent to effectively prevent and treat metabolic syndrome and cardiovascular complications is of crucial importance. Several conventional medicines are available in market. However, these are believed to have side effects. Therefore, alternative medicines are of present day research interest. In this paper we have, tried to explore the possible role of a recently known antioxidant, pyrroloquinoline quinone (PQQ) in regulating DM induced cardiovascular problems.

PQQ, an anionic water soluble compound, was initially proposed to act as a cofactor of many bacterial dehydrogenases. ${ }^{7}$ It was also found to be neuroprotective as it prevents oxidative stress-induced neurotoxicity and neuronal death. In recent years, it has been reported that PQQ scavenges ROS, protects from oxidative stress and decreases the levels of free radicals as well as lipid peroxidation (LPO) ${ }^{8-10}$ One report also suggested that PQQ reduces myocardial infarct size and improves cardiac function. ${ }^{11}$ Both in vivo and in vitro 
studies have shown that PQQ can protect against several types of oxidative damages and irradiation injury. Recently, workers found not only the involvement of ROS in the pathogenesis of CVDs, but also suggested the use of antioxidants which play a major role in reducing the oxidative stress by scavenging the excess free radicals. ${ }^{8,9}$ In recent years several compounds with antioxidant properties have been found to be beneficial and may protect or restore physiological function in diabetes associated CVDs, mainly plant based compounds have been investigated in details. ${ }^{12}$ However, the recently known PQQ has not been tried with respect to its cardio-protective potential in diabetes, if any. An attempt has now been made to evaluate its role in the diabetes-induced CVDs and associated oxidative damage in heart.

\section{Materials and methods}

\section{Animals}

Swiss albino male mice, 7-8 weeks old weighing $30 \pm 2(\mathrm{~g})$ were housed in polypropylene cages in a standard photoperiod (14h light:10h dark) and temperature $\left(27 \pm 1^{\circ} \mathrm{C}\right)$ controlled room with the provision of laboratory feed (Gold Mohur feed, Hindustan Lever Limited, Mumbai, India) and water ad libitum. Animals were maintained in accordance with the guidelines of committee for the purpose of control and supervision of experiments on animals (CPCSEA), Ministry of Environment, Forest and Climate Change, New Delhi, Govt. of India. (Reg. No. 779/Po/Ere/S/03/CPCSEA).

\section{Induction of diabetes to experimental mice}

Streptozotocin (STZ) is a commonly used diabetogenic agent. ${ }^{13}$ Diabetes was induced by a single intraperitoneal injection of a freshly buffered $(0.1 \mathrm{M}$ citrate, $\mathrm{pH} 4.5)$ solution of STZ (Sigma-Alderich chemicals) single dose of $150 \mathrm{mg} / \mathrm{kg} .{ }^{14}$ After $72 \mathrm{~h} / 3$ days of STZ administration, the tail vein blood was collected to determine fasting blood glucose level. Only mice with fasting blood glucose over $250 \mathrm{mg} / \mathrm{dl}$ were considered diabetic and included in the experiments.

\section{Experimental design}

Fourty-nine healthy male mice (7-8 weeks old) were randomly divided into seven groups of seven each. Group I animals receiving single intraperitoneal (i.p) injection of citrate buffer $(0.1 \mathrm{ml}, 0.1 \mathrm{M}$ citrate, $\mathrm{pH} 4.5)$ solution served as control. Group II received single i.p injection of citrate buffer $(0.1 \mathrm{ml}, 0.1 \mathrm{M}$ citrate, $\mathrm{pH} 4.5)$ solution along with PQQ $20 \mathrm{mg} / \mathrm{kg}(0.1 \mathrm{ml}$, i.p) for 15 days; whereas those of group III, IV, V, VI and VII received STZ i.p. After rendering DM/ hyperglycemia, animals of group IV, V and VI were treated i.p. with three different doses of PQQ $(5,10$ and $20 \mathrm{mg} / \mathrm{kg} /$ day, respectively for 15 days); ${ }^{11,15}$ group VII animals received Vit.C (50mg/kg/day (i.p.), for 15 days). ${ }^{16}$ Total experimentation time duration was 18 days $\left(1^{\text {st }}\right.$ 3 days for rendering diabetes and $4^{\text {th }}$ to $18^{\text {th }}$ day for PQQ and Vit. C treatment).

\section{Blood sampling and serum preparation}

At the end of experiment, animals were sacrificed by a mild ether anaesthesia and blood from each animal was collected in clean tubes. Blood samples were centrifuged at 3000rpm for $5 \mathrm{~min}$; serum was separated and stored at $-20^{\circ} \mathrm{C}$ until estimations of different biochemical parameters including serum concentrations of insulin, lactate dehydrogenase (LDH), glucose, cholesterol, triglyceride and high density lipoproteins (HDL-C).

\section{Tissue isolation and homogenate preparation}

After sacrificing a the animals were exsanguinated and heart from each one was removed quickly, washed with phosphate buffered saline (PBS) and tissue slices were weighed and homogenized in ice cold PBS (0.1M, pH 7.4), to the final concentration of tissue at $100 \mathrm{mg} / \mathrm{ml}$ of PBS buffer. The homogenate was centrifuged at $15,000 \mathrm{~g}$ for $30 \mathrm{~min}$ at $4{ }^{\circ} \mathrm{C}$ and; supernatants were collected and stored at $-20^{\circ} \mathrm{C}$ until use.

\section{Biochemical estimations}

Serum insulin was measured by using commercially available ELISA kit (IRI Research Inc. lake view, Canada). Serum LDH level was measured by using commercially available enzymatic kit (ERBA diagnostic Pvt. Ltd, Germany). LPO level in tissues homogenate was measured by the method of Ohkawa et al. ${ }^{17}$ The LOOH activity was measured by the method of Griffiths et al. ${ }^{18}$ Activity of SOD was determined by the pyrogallol auto-oxidation inhibition assay method of Marklund et al. ${ }^{19}$ Catalase activity was estimated following the method of Aebi. ${ }^{20}$ The GPx activity was calculated according to the method of Mohandas et al. ${ }^{21}$ Tissue glutathione content (reduced sulfhydryl groups) was estimated following the protocol of Ellman..$^{22}$ Tissue protein content was determined following the method of Lowry et al., ${ }^{23}$ using bovine serum albumin (BSA) as a standard. Serum glucose, total cholesterol, triglyceride, HDL-C level was estimated by using commercially available kit (ERBA diagnostic Pvt. Ltd. Germany). LDL-C, VLDL-C were calculated following the equation of Friedwald et al., ${ }^{24}$ and RR value was calculated by following the equation of Chockalingam et al., ${ }^{25} \mathrm{AI}$ was calculated by following the equation: $=(\mathrm{TC}-\mathrm{HDL}-\mathrm{C}) / \mathrm{HDL}-\mathrm{C}$.

\section{Histopathologic studies}

Histopathological slides were prepared following the method of Deepa et al., ${ }^{26}$ after exsanguinations, a portion of the cardiac tissue was washed with ice chilled phosphate buffer $(0.1 \mathrm{M}, \mathrm{pH} 7.4)$ and fixed in $10 \%$ formaldehyde for 24 hours. The tissues were dehydrated in the descending grades of isopropanol, finally cleared in xylene and then embedded in molten paraffin wax. Sections were cut at 5- $\mu \mathrm{m}$ thickness, stained with hematoxylin and eosin, and scrutinized under clinical microscope (Lieca-DM RA, Research Microscope system, Germany) and the slides were scanned using attached camera.

\section{Statistical analysis}

Results have been expressed as means \pm SEM $(n=7)$. For the statistical evaluation, analysis of variance (ANOVA) was used followed by post hoc Newman-Keul's Multiple Comparison Test using the trial version of Prism 5 software (GraphPad Software, Inc., La Jolla, CA, USA) and Microsoft Office 2003 for windows. A "p" value of 0.05 or less is considered to be significant.

\section{Results}

\section{Alterations in body weight}

Alterations in the body weight (g) of the experimental animals of different treated groups are depicted in Table 1. During the course of the present study, it was observed that the body weight of the normal/ control animals as well as in PQQ $(20 \mathrm{mg} / \mathrm{kg})$ treated normoglycemic animals showed a normal growth at the end of experiment with a percent increase of $20 \%$ and $20.45 \%$ respectively. After completion of experimentation; comparing the body weight of $1^{\text {st }}$ day, $4^{\text {th }}$ day 
(the day when PQQ administration was started) and $18^{\text {th }}$ day in the respective group animals, a loss in body weight was observed in the STZ treated in all the group of animals on $4^{\text {th }}$ day, as compared to the body weight of respective group animals on $1^{\text {st }}$ day. However, net body weight loses of $21.90 \%$ was observed in animals treated with only STZ. After administration of PQQ $(5,10 \& 20 \mathrm{mg})$ and Vit. C at

Table I Alterations in the body weight (g) on Ist and on $18^{\text {th }}$ (last) day of experimentation in different experimental groups of animals

\begin{tabular}{|c|c|c|c|c|}
\hline \multirow[t]{2}{*}{ Groups } & \multicolumn{4}{|c|}{ Alteration in body weight (g) } \\
\hline & Ist day $^{\text {st }}$ & $4^{\text {th }}$ day & $18^{\text {th }}$ day & (\% Changed) \\
\hline Control & $30.00 \pm 1.212$ & $31.50 \pm 1.002$ & $36.00 \pm 1.154$ & $(20.00 \% \uparrow)$ \\
\hline PQQ 20mg & $30.55 \pm 1.554$ & $31.40 \pm 0.914$ & $36.75 \pm 1.250$ & $(20.45 \% \uparrow)$ \\
\hline STZ & $29.45 \pm 1.363$ & $26.00 \pm 0.925$ & $23.00 \pm 1.290$ & $(21.90 \% \downarrow)$ \\
\hline STZ+PQQ 5mg & $29.85 \pm 1.069$ & $26.40 \pm 1.121$ & $28.00 \pm 1.212$ & $(06.19 \% \downarrow)$ \\
\hline STZ+PQQ IOmg & $30.00 \pm 1.290$ & $26.50 \pm|.23|$ & $28.5 I \pm 0.975$ & $(04.96 \% \downarrow)$ \\
\hline STZ+PQQ 20mg & $30.00 \pm 1.116$ & $26.80 \pm 0.936$ & $29.50 \pm 0.487$ & $(01.66 \% \downarrow)$ \\
\hline STZ+Vit. C 50mg & $30.00 \pm 1.519$ & $27.00 \pm 0.936$ & $27.50 \pm 0.45 I$ & $(08.33 \% \downarrow)$ \\
\hline
\end{tabular}

Data are expressed in mean \pm SEM $(n=7)$. Increased or decreased ( $\uparrow$ or $\downarrow$ ) percent (\%) body weight changes, calculated as compared to its value in the respective group, from Ist day and I8th day.

\section{Serum insulin, LDH, LPO and LOOH level}

Changes in serum insulin concentrations are illustrated in Figure 1A. Insulin was significantly decreased in the STZ-induced diabetic mice $(\mathrm{p}<0.001$, as compared to that of control ones). Following administration of $20 \mathrm{mg} / \mathrm{kg}$ PQQ to normoglycemic mice, insulin level was increased but not significantly as compared to the control animals. However, administration of PQQ at a dose of $20 \mathrm{mg} / \mathrm{kg}$ in diabetic animals brought a marked increase in insulin level $(\mathrm{p}<0.001)$ as compared to that of STZ-induced diabetic mice. While no significant alteration was observed in $5 \mathrm{mg} / \mathrm{kg}$ body weight PQQ and Vit. C $(50 \mathrm{mg} / \mathrm{kg})$ treated diabetic animals, $10 \mathrm{mg} / \mathrm{kg}$ body weight of PQQ significantly $(p<0.05)$ enhanced the level of insulin.

While serum LDH concentrations was significantly increased in the STZ-induced diabetic mice $(\mathrm{p}<0.001$, as compared to that of control ones), administration of $20 \mathrm{mg} / \mathrm{kg}$ PQQ to normoglycemic mice, did not significantly alter its concentration. When PQQ (5, 10 and $20 \mathrm{mg} / \mathrm{kg}$ ) was administered to STZ-treated mice, a marked decrease in LDH level $(\mathrm{p}<0.001)$ as compared to that of STZ-induced diabetic mice was observed (Figure 2). Following the administration of Vit. C $(50 \mathrm{mg} / \mathrm{kg})$ in STZ treated animals a significant $(\mathrm{p}<0.05)$ decrease in LDH level was observed. While no significant alteration was observed in $5 \mathrm{mg} / \mathrm{kg}$ of PQQ treated STZ-induced diabetic animals; PQQ at $10 \mathrm{mg} / \mathrm{kg}$ dose significantly $(\mathrm{p}<0.05)$ decreased the level of LDH in STZ treated animals (Figure 1B). Cardiac LPO was increased significantly $(\mathrm{p}<0.001)$ following the STZ administration. However, when PQQ $(5,10$ and $20 \mathrm{mg} / \mathrm{kg} / \mathrm{d}$ ) was administered in diabetic animals, a significant $(\mathrm{p}<0.001)$ decreased LPO was observed in all the tested doses. Administration of Vit. C in STZ-treated animals significantly decreased the LPO level in STZ treated animals $(\mathrm{p}<0.001)$, while $20 \mathrm{mg} / \mathrm{kg}$ of PQQ in normoglycemic animals did not significantly alter cardiac LPO (Figure 1C). With respect to cardiac LOOH level, it was increased significantly $(\mathrm{p}<0.001)$ following the STZ administration. However, when different doses of PQQ (5, 10 and $20 \mathrm{mg} / \mathrm{kg} / \mathrm{d}$ ) were administered to the diabetic animals, a significant $(\mathrm{p}<0.001$, for all) decrease in $\mathrm{LOOH}$ level was observed with all the tested doses. However, $20 \mathrm{mg} / \mathrm{kg}$ of PQQ in normoglycemic animals
$50 \mathrm{mg} / \mathrm{kg}$ for 15 days there, no further body weight loss was observed in respective group of animals as compared to that of $4^{\text {th }}$ and $18^{\text {th }}$ day, indicating that the administration of PQQ and Vit. C in STZ-treated animals protected from the diabetes-induced body weight loss (Table $1)$. did not significantly alter $\mathrm{LOOH}$ as compared to the value of control animals. Administration of Vit. $\mathrm{C}$ in diabetic animals brought a marked decrease in LOOH level $(p<0.001)$, as compared to that of STZ-induced diabetic mice (Figure 1D).

\section{Alterations in cardiac tissue antioxidants level}

Cardiac SOD activity was decreased significantly following the STZ administration $(\mathrm{p}<0.01)$. However, only in $20 \mathrm{mg} / \mathrm{kg}$ PQQ and Vit. C $(50 \mathrm{mg} / \mathrm{kg})$ a treated diabetic animal, a significant increase in its SOD level was observed $(p<0.001$ and $p<0.05$, respectively) (Figure 2A). Similar trend was also noticed in CAT activity, that was decreased significantly following the STZ administration $(p<0.01)$, and only in $20 \mathrm{mg} / \mathrm{kg}$ of PQQ and $50 \mathrm{mg} / \mathrm{kg}$ of Vit. C treatment in diabetic animals a significant increase in SOD level was observed $(p<0.01$ and $p<0.05$, respectively) (Figure $2 B$ ). With respect to GPx activity, following the STZ administration there was a significant decrease $(\mathrm{p}<0.05)$. However, when PQQ $(5,10$ and $20 \mathrm{mg} / \mathrm{kg} / \mathrm{d})$ was administered in the diabetic animals, a significant $(p<0.05, p<0.05$ and $\mathrm{p}<0.001$ respectively) increase in GPx activity was observed with all the tested doses. Administration of Vit. C $(50 \mathrm{mg} / \mathrm{kg})$ in diabetic animals also significant increased GPx level (Figure 2C). While STZ administration significantly $(\mathrm{p}<0.001)$ decreased GSH level, on administration of PQQ $(20 \mathrm{mg} / \mathrm{kg} / \mathrm{d})$ in the diabetic animals, a significant $(p<0.001)$ increase in GSH level was observed with all the tested doses; while on administration of Vit. C $(50 \mathrm{mg} / \mathrm{kg})$ in STZ treated animals, a significant $(\mathrm{p}<0.01)$ increase in GSH level was observed (Figure 2D).

\section{Serum glucose, lipid profile, $\mathbf{R} \mathbf{R}$ and $\mathbf{A l}$}

With respect to different serum parameters, a significant $(p<0.001)$ increase in the level of glucose, total cholesterol and triglyceride (Figure 3A); LDL-C, VLDL-C, RR ratio and AI (Figure 3B) was observed following the STZ administration. However, when PQQ (5, 10 and $20 \mathrm{mg} / \mathrm{kg} / \mathrm{d}$ ) was administered in the diabetic animals; out of three doses of PQQ, 20mg/ kg markedly reversed all these indices and the reversal percentages were also found to be better as compared 
to other two doses. While, on administration of Vit. C $(50 \mathrm{mg} / \mathrm{kg})$ to STZ-treated animals, it significantly reversed the aforesaid indices as compared to that of STZ-induced diabetic animals, except VLDL-C where no significant alterations was observed; With respect to serum HDL $-C$ level, it was decreased significantly $(p<0.001)$ following the STZ administration, and on PQQ $(5,10$ and $20 \mathrm{mg} / \mathrm{kg} / \mathrm{d})$ administration in the diabetic animals, a significant $(\mathrm{p}<0.001)$ increase was observed with all 3 tested doses. On administration of Vit. C $(50 \mathrm{mg} / \mathrm{kg})$ to STZtreated animals, it also significantly $(\mathrm{p}<0.01)$ increased the HDL-C level (Figure 3B).
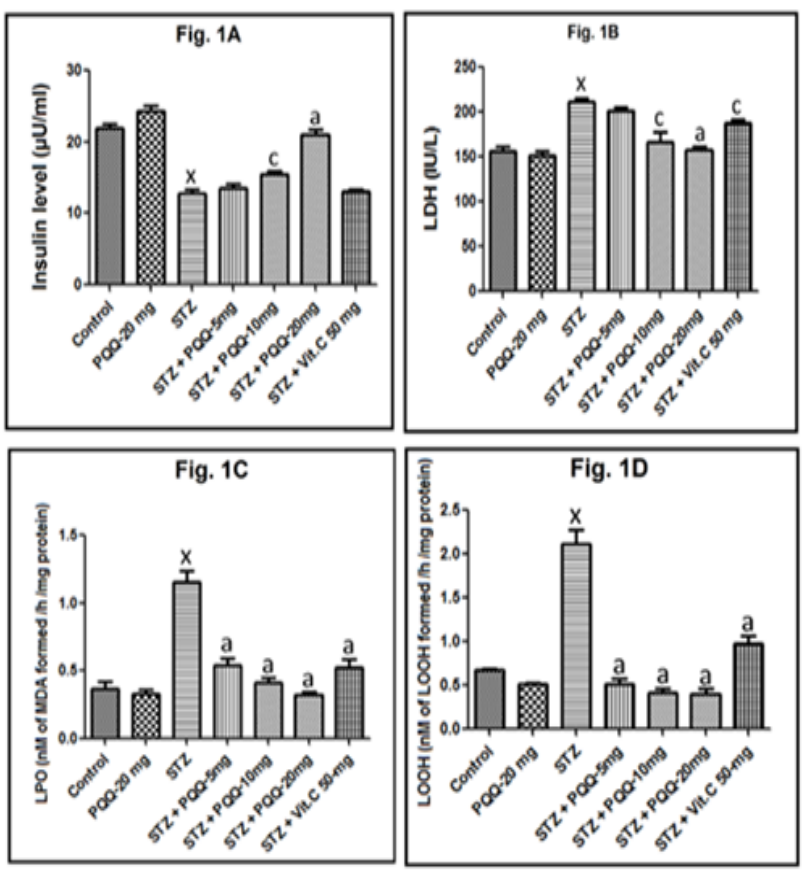

Figure I Effects of PQQ (5, 10 and $20 \mathrm{mg} / \mathrm{kg} / \mathrm{d}$, i.p.) and vitamin $C$ for 15 days on.
A. Insulin level $(\mu \mathrm{U} / \mathrm{ml})$
B. LDH level $(\mu \mathrm{U} / \mathrm{ml})$
C. LPO (nM of MDA formed $/ \mathrm{h} / \mathrm{mg}$ protein)

D. LOOH ( $\mathrm{nM}$ of LOOH formed /h /mg protein). Data are mean \pm S.E.M. $(n=7) . x, P<0.001$ as compared to the respective control values. $a, P<$ $0.00 \mathrm{I}$ and $\mathrm{c}, \mathrm{P}<0.05$ as compared to the respective $\mathrm{STZ}$ treated values. STZ, Streptozotocin; PQQ, pyrroloquinoline quinone; LDH, lactate dehydrogenase; LPO, lipid peroxidation; $\mathrm{LOOH}$, lipid hyroperoxidation; Vit. C,Vitamin C

\section{Histopathological observations}

With respect to histopathological observations of heart; the control group animals showed normal morphological and cyto-architecture of the myocardium, but in STZ-treated mice, the necrotic changes, disruption of myofibrils, vacuolization of the cytoplasm, patchy necrosis and inflammatory cells were observed in myocardial tissues. However, administration of PQQ $(5,10 \& 20 \mathrm{mg} / \mathrm{kg})$ to STZ treated mice ameliorated these deleterious effects in a dose dependent manner. The histology of heart tissues of PQQ treated animals showed moderate loss of myofibrils and vacuolization of the cytoplasm as well as showed regenerative changes in myocardial tissue. PQQ treatment in diabetic animals provided optimal protection at a dose of $20 \mathrm{mg} / \mathrm{kg}$ body weight, suggesting the protective action of PQQ against oxidative stress-mediated cardiac damage. Similar beneficial effects were observed after administration of Vit. C to STZ treated animals. No significant histological changes were observed by the administration of PQQ $(20 \mathrm{mg} / \mathrm{kg})$ to normoglycemic animals (Figure 4). When we compared the effects of PQQ (20mg) and Vit. C (50mg) in STZ-induced diabetic animals, interestingly better ameliorate effects were observed in PQQ than Vit. C to ameliorate diabetesinduced cardiovascular problems (Table 2).
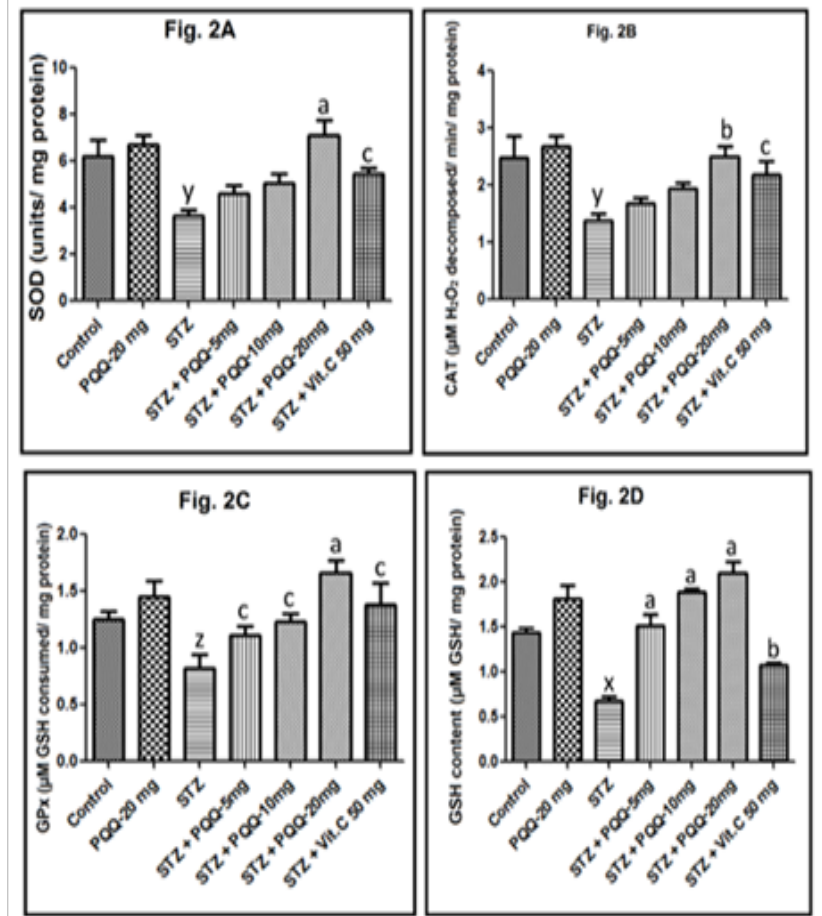

Figure 2 Effects of different concentrations of PQQ (5, 10 and $20 \mathrm{mg} / \mathrm{kg} / \mathrm{d}$, i.p.) and vitamin $C(50 \mathrm{mg})$ for 15 days on cardiac.

A. SOD (units/mg protein)

B. CAT ( $\mu \mathrm{M} \mathrm{H} 2 \mathrm{O} 2$ decomposed/ min/ mg protein)

C. GPx ( $\mu$ M GSH consumed/ mg protein)

D. GSH content ( $\mu$ M GSH/mg protein). Data are mean \pm S.E.M. $(n=7) . x, P<$ $0.00 \mathrm{I}$ as compared to the respective control values. $\mathrm{a}, \mathrm{P}<0.00 \mathrm{I}$ and c, $\mathrm{P}<0.05$ as compared to the respective STZ treated values. STZ, streptozotocin; PQQ, pyrroloquinoline quinone; SOD, superoxide dismutase; CAT, catalase; GPx, glutathione peroxidase; GSH, reduced glutathione; Vit. C,Vitamin C

Table 2 Comparison between effects of PQQ $(20 \mathrm{mg})$ and Vit. C (50mg) in percent (\%) amelioration of different indices as compared to STZ treated diabetic animal

\begin{tabular}{lll}
\hline $\begin{array}{l}\text { Parameters/ } \\
\text { Indices }\end{array}$ & STZ + PQQ 20mg & STZ + Vit. C 50mg \\
\hline Insulin & $64 \%$ & $2 \%$ \\
LDH & $25 \%$ & $11 \%$ \\
LPO & $72 \%$ & $37 \%$ \\
SOD & $94 \%$ & $48 \%$ \\
CAT & $81 \%$ & $57 \%$ \\
\hline GPx & $102 \%$ & $68 \%$ \\
GSH & $207 \%$ & $58 \%$ \\
Glucose & $55 \%$ & $22 \%$ \\
\hline
\end{tabular}


Table Continued.

\begin{tabular}{lll}
$\begin{array}{l}\text { Parameters/ } \\
\text { Indices }\end{array}$ & STZ + PQQ 20mg & STZ + Vit. C 50mg \\
\hline TC & $43 \%$ & $26 \%$ \\
TG & $38 \%$ & $16 \%$ \\
HDL-C & $37 \%$ & $7 \%$ \\
LDL-C & $63 \%$ & $21 \%$ \\
VLDL-C & $38 \%$ & $11 \%$ \\
RR-Value & $65 \%$ & $41 \%$ \\
AI & $71 \%$ & $37 \%$
\end{tabular}

Ameliorating percent (\%) were calculated as compared to the PQQ (20mg) and Vit. C (50mg) treated group to STZ-induced diabetic group animals.

STZ, streptozotocin; PQQ, pyrroloquinoline quinone; LDH, lactate dehydrogenase; LPO, lipid peroxidation; Vit. C, vitamin c; SOD, superoxide dismutase; CAT, catalase; GPx, glutathione peroxidase; GSH, reduced glutathione; TC, total cholesterol; TG, triglyceride; HDL-C, high density lipoprotein; LDL-C, low density lipoprotein; VLDL-C, very low density lipoprotein; $\mathrm{RR}$, relative risk; $\mathrm{Al}$, atherogenic index

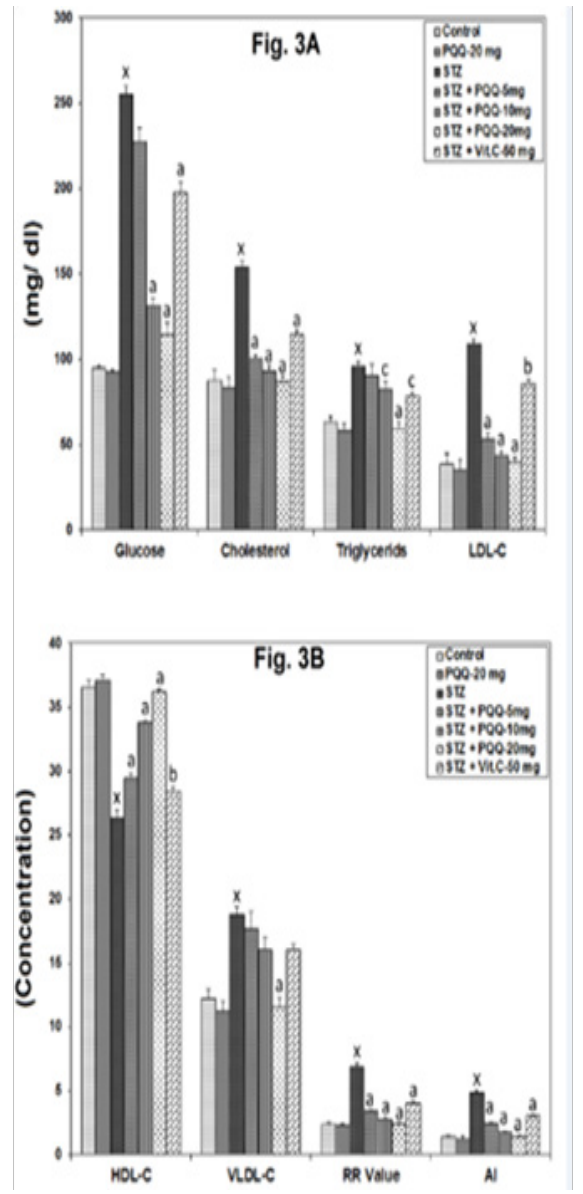

Figure 3 Effects of PQQ (5, 10 and $20 \mathrm{mg})$ and vitamin $C$ for 15 days on serum.

A. Glucose, cholesterol, triglyceride and LDL-C (mg/dl)

B. HDL-C,VLDL-C, RR value and AI $(\mathrm{mg} / \mathrm{dl})$. Data are mean $\pm \mathrm{SEM}(\mathrm{n}=7) . \mathrm{x}$, $\mathrm{P}<0.00$ I compared to the respective control values. $\mathrm{a}, \mathrm{p}<0.00 \mathrm{I}, \mathrm{b}, \mathrm{p}<0.0$ I and $c, p<0.05$ as compared to the respective STZ treated value. STZ, Streptozotocin; PQQ, pyrroloquinoline quinone; LDL-C, low density lipoprotein; HDL-C, high density lipoprotein;VLDL-C, very low density lipoprotein;TC, Total cholesterol; RR, relative risk;Vit. C,Vitamin C

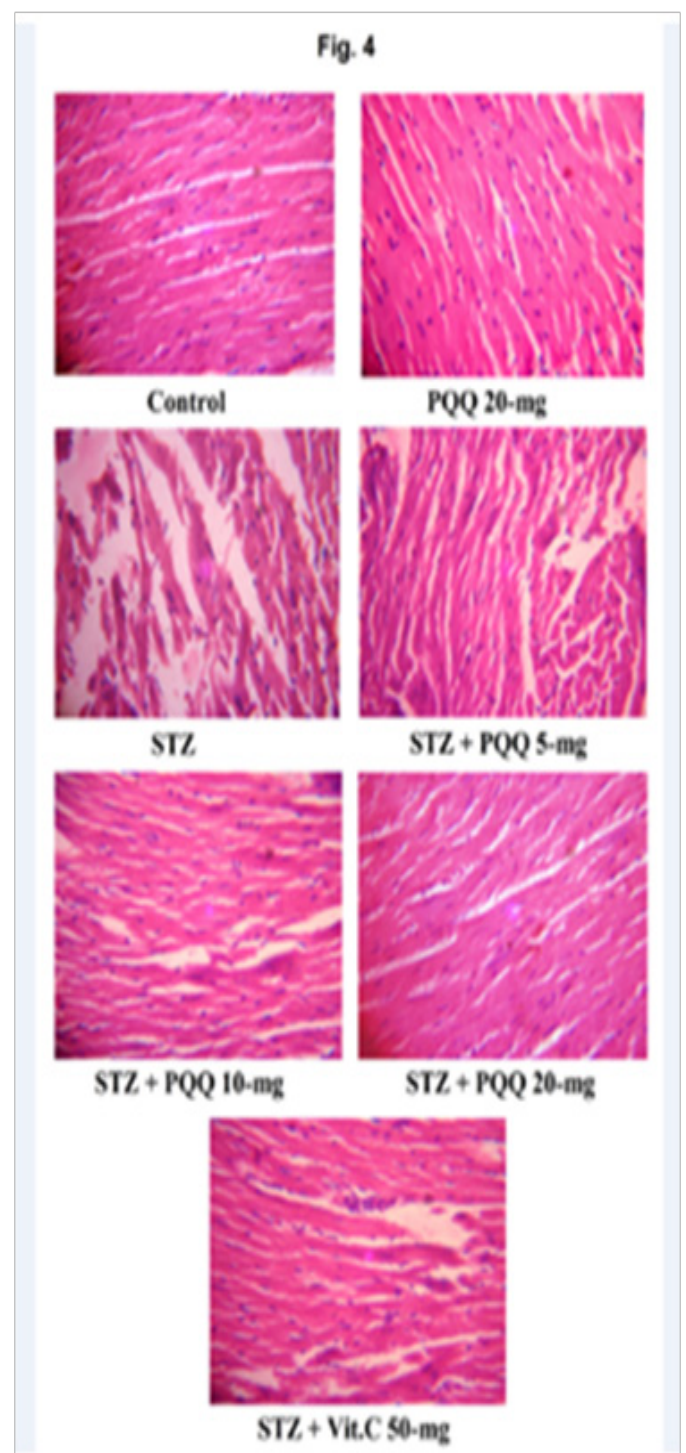

Figure 4 Heart histology of control; PQQ treated; STZ treated; STZ + PQQ treated $(5,10$ \& $20 \mathrm{mg} / \mathrm{kg}$ body weight); STZ + Vit. C $(50 \mathrm{mg} / \mathrm{kg}$ body weight) treated mice.The staining was done with hematoxylin-eosin. Original magnification $\times 40$. Photomicrographs are representative samples from each treated group.

\section{Discussion}

Results of the present investigation clearly indicate the antioxidative potential of the test drug (PQQ) in the regulation of cardiac oxidative damages and cardiovascular problems, induced by dibetogenic drug (STZ) in mice; suggesting that PQQ has the potential to prevent diabetes-induced cardiovascular problems. This was evident by reversal of STZ-induced adverse effects in mice with respect to most of the tested indices. Interestingly the comparative study of PQQ and Vit. C effects indicated better potential of the latter than the former. PQQ is known to scavenge ROS and to protect cells from oxidative stress-induced damage. It very often improves the activities of freeradical (FR) scavenging enzymes and decreases the levels of FR as well as tissue LPO. ${ }^{8,9}$ Both in vivo and in vitro studies have shown that PQQ can protect against several types of oxidative damages and irradiation injury. ${ }^{8,27}$ Potential role of PQQ, especially in DM, a disease which is strongly connected to cardiovascular complications 
was not yet known. Now the present study focuses on the effect of PQQ on the cardiovascular problems in STZ-induced diabetic mice.

FR mechanisms have been implicated in the pathology of several diseases, including DM. ${ }^{28}$ Our observations also indicate the involvement of FR scavenging in diabetic mice. Recently much focuses have been given on the oxidative stress and it is suggested that ROS may be the key to the pathogenesis of various diabetic complications. In the present investigation, STZ administration caused oxidative damage, represented by marked decrease in SOD, CAT and GPx activity and GSH content; along with an increase in LPO and LOOH in cardiac tissues as reported earlier by others. ${ }^{29,30}$ However, PQQ administration reversed these oxidative changes clearly indicating the antioxidative potential of the test drug, in DMinduced mouse heart. Even the diabetes related indices such as serum LDH, glucose, cholesterol, triglyceride, LDL-C, VLDL-C, AI and RR ratio, all were decreased by PQQ. These anti-diabetic effects of PQQ were supported by its antioxidative properties, as PQQ not only inhibited tissue LPO but also enhanced the serum insulin and HDL, as well as cellular antioxidants. The beneficial effects were further supported by near normal histopathological features observed in cardiac tissues of PQQ treated animals.

STZ is a chemical that particularly causes toxicity to the insulinproducing beta cells of the pancreas in mammals and is widely used in medical research to create an animal model of DM. In the present study, STZ administration led to hyperglycemia and decreased the insulin level. STZ-induced oxidative impairment was confirmed by significant increase in glucose and LDH levels, with a parallel decrease in the activity of antioxidant enzymes. In the present study, simultaneous administration of PQQ in the STZ treated animals significantly increased the serum insulin and levels of cardiac antioxidants, apart from a decrease in the glucose concentration. PQQ-induced reduced blood glucose level and oxidative stress, clearly suggests that test drug has high antioxidative potential, which is further supported by an improvement in histopathologic changes near to normal cellular architecture in cardiac tissue (Figure 4). Of course, PQQ administration in control animal did not affect the blood glucose level significantly.

Lactate dehydrogenase (LDH), a cytosolic enzyme, predominantly found in cardiac tissues, is an important hallmark of myocardial injury. ${ }^{31}$ In the present study, LDH level in STZ-induced diabetic mice was significantly higher as compared to the control animals, as also reported earlier. ${ }^{32}$ This elevated LDH level, observed in the experimental diabetic animals may be associated with impaired insulin secretion..$^{33}$ In fact, increased activity of LDH interferes with normal glucose metabolism and insulin secretion in the $\beta$-cells of pancreas and it may therefore be directly responsible for insulin secretory defects in diabetes. There are some reports which suggest that treatment with plant extracts having antioxidant properties reverses the LDH level in diabetic animals. ${ }^{34}$ Therefore, in the present study it may be assumed that PQQ, being a strong antioxidant, its simultaneous administration might have reduced the LDH near to normal level reversing the STZinduced adverse effects in heart. Antioxidative potential of PQQ was further supported by inhibition in tissue LPO and LOOH.

Determination of MDA and $\mathrm{LOOH}$ levels reflects the status of LPO. An increased level of MDA, in DM suggests that hyperglycaemia induces peroxidative reactions in lipids. In our study, both MDA and $\mathrm{LOOH}$ levels in heart tissues of diabetic mice were significantly higher, similar to the findings of another study. ${ }^{35}$ According to
Selvakumar et al. ${ }^{36}$ LPO is an important manifestation of ROSinduced oxidative damage, related to changes in membrane structures and enzyme denaturation. Moreover, oxidative stress plays a role in the development of diabetic complications. LPO is also induced by protein glycation and glucose auto-oxidation that can further lead to the formation of free radicals. These free radicals might play a role in DNA damage and protein modification reactions. However, in the present study simultaneous administration of PQQ in the STZ treatment group significantly decreased the MDA and LOOH levels in heart tissue, indicating its FR scavenging property. This antioxidative property of PQQ related to its electrophilic nature for which it forms stable adducts with carbonyl reagents. These characteristics provide PQQ the ability to oxidize the redox modulatory site, thus conferring protection against ROS-mediated cell injury. ${ }^{37}$ PQQ-induced reduction in intracellular ROS levels hypothesizes that it acts directly or indirectly as a potent free radical scavenger. Probably for this reason LPO level was normalized in PQQ treated animals. However, the site of action of PQQ, either intra-mitochondrial or in the cytoplasm, or both, is yet to be ascertained.

Importance of PQQ was also supported by positive alterations in the activities of antioxidants. A marked increase in different cellular antioxidants such as SOD, CAT and GPx was found in diabetic mice after administration of PQQ, further confirming its antioxidative role. These enzymes play crucial role in antioxidant defense as they provide a protective mechanism against oxidative stress by converting FR/ reactive oxygen intermediates to non-radical products. SOD and GPX are major enzymes that scavenge harmful ROS..$^{15,38}$ SOD catalytically converts superoxide radicals to $\mathrm{H}_{2} \mathrm{O}_{2}$ and GPx that metabolizes $\mathrm{H}_{2} \mathrm{O}_{2}$ to $\mathrm{H}_{2} \mathrm{O}$ and thereby reduces the free radicals. In the present study, SOD level was low in diabetic groups, while after administration of PQQ it was increased significantly. Similarly, CAT activity was also increased in these PQQ-treated diabetic animals.

Glutathione, another well-known antioxidant provides the major protection against cellular oxidative damages and maintains $\mathrm{SH}$ level in proteins. It forms reduced GSH from oxidized glutathione that in turn reduces hydrogen peroxide, lipid peroxides and free radicals. In STZ-treated animals its level was reduced as was seen earlier in DM. ${ }^{39,40}$ However, administration of PQQ increased the GSH level, further supporting its antioxidative role. GPx is a cytosolic enzyme that complements with CAT in order to detoxify hydrogen peroxide and organic hydroperoxide..$^{41}$ Reduction of hydroperoxide by glutathione in the presence of GPx protects mammalian cells from oxidative damages. Although in the present investigation a significant decrease in GPx activity in STZ-induced DM group was observed, after PQQ administration there was a marked increase in its level was observed. This again supported the antioxidative and protective nature of PQQ in STZ-induced diabetes and associated cardiac problems.

Lipid profile and atherogenic index have been shown to be important parameters for analysis of metabolic disturbances including CVDs. Significant alterations in the levels of lipids make the individuals more susceptible to develop cardiac problems. ${ }^{42}$ An increased level of cholesterol, $\mathrm{LDL}-\mathrm{C}$ and VLDL-C is also often found in DM. ${ }^{43}$ Therefore, lipid profile is also considered as a key marker for diabetes associated CVDs. ${ }^{44,45}$ In our study, interestingly the beneficial effect of PQQ was also reflected in the alterations of different lipids. While, STZ administration increased the serum, cholesterol, triglyceride, LDL-C and VLDL-C levels as observed earlier it by others ${ }^{46}$ PQQ administration reduced them. This was also expected, because diabetic patients and diabetic animals do exhibit 
disturbed lipid metabolism and show hyperlipidemia. ${ }^{47,48}$ It was also reported earlier that there is a negative correlation between serum levels of triglycerides and VLDL-C to serum insulin concentration ${ }^{49}$ as is observed now. Interestingly, simultaneous PQQ administration decreased the cholesterol and triglyceride levels as was observed earlier. ${ }^{50,51}$ Because, hyperlipidemia is believed to be ameliorated by the administration of antioxidants, ${ }^{52}$ it may be assumed that PQQ, being a strong antioxidant, could reverse the STZ-induced adverse effects. Diabetes exhibits the attenuation of antioxidant capacity and/ or immune function, and then disturbs lipid metabolism ${ }^{48}$ showing high triglyceride cholesterol and CVDs. ${ }^{47} \mathrm{LDL}-\mathrm{C}$ level was increased in STZ-induced diabetic animals, that might have resulted from glycosylation of the lysyl residues of apoprotein B, which normally decreases LDL-C metabolism through a decrease in the affinity of LDL $-\mathrm{C}$ for its receptors. Our results also show a decrease in serum HDL in STZ-induced diabetic mice, as observed earlier in untreated diabetics. ${ }^{53}$ Low HDL level is a risk factor for CVDs and also for DM. ${ }^{43,44,54}$ Moreover, an increase in HDL cholesterol is considered to reduce risk of coronary heart disease as HDL exerts a protective effect by enhancing reverse cholesterol transport through scavenging excess cholesterol from peripheral tissues and eventual elimination from the body. ${ }^{54}$ It also inhibits the oxidation of LDL-C as well as the atherogenic effects of oxidized LDL-C..$^{55}$ The mechanisms of the hypolipidemic actions of PQQ are not known. Probably this has been mediated through improved insulin secretion and/ or action, because insulin is known to lower lipid levels and to normalize lipids in STZinduced diabetic. ${ }^{56}$ Ikewuchi, ${ }^{57}$ reported that atherogenic index is a powerful indicator of the risk of heart diseases and higher the value of AI, the higher the risk of developing CVDs \& vice versa. In the present study AI and RR-values were significantly higher in STZinduced diabetic animals and simultaneous administration of PQQ significantly reduced both the indices indicating its potential to reduce CVDs. This decrease in the atherogenic index and RR-value by PQQ is primarily due to increased HDL level.

Since nothing was known on the role of PQQ in regulating DM associated oxidative damages in cardiac tissue, the present report appears to be the first one that clearly indicates the efficacy of PQQ in regulating adverse effects of DM in cardiac tissues. PQQ was earlier known to regulate different abnormalities, ${ }^{11,51}$ which are indirectly associated with diabetic complications. Now our findings ascertain that PQQ has also the potential to regulate STZ-induced damage to cardiac tissues. One possible mechanism of its efficacy could be its strong antioxidant property, as suggested in some other studies, in which the free radical scavenging activity of PQQ has been clearly shown. ${ }^{10,51}$ The other possible mechanism of action of PQQ in ameliorating diabetes could be through peroxisome proliferatoractivated receptor gamma coactivator 1 -alpha (PGC-1 $\alpha$ ); PQQ stimulates PGC-1 $\alpha$ expression. ${ }^{58}$ Previously it was reported that there is a close relationship among PGC- $1 \alpha$ function and diabetes. ${ }^{59} \mathrm{PGC}-$ $1 \alpha$ is a potent stimulator of mitochondrial biogenesis and respiration. As a transcription co-activator, it has also been shown to regulate genes of the ROS detoxifying systems, thus protecting against oxidative stress. ${ }^{60}$ Other observations also suggest that peroxisome proliferator-activated receptor (PPAR) signalling regulate pathway is involved in the lipid and glucose metabolism and activation of PPAR may restores the islet function. ${ }^{49,61}$ We suggest that, in the present investigation also the effects of PQQ in regulating DM induced oxidative damages might have been mediated through stimulation of PGC-1 $\alpha$.

Whatever may be the exact mechanism of action, from our findings it is clearly evident that PQQ has the potential to ameliorate STZ-induced oxidative stress in cardic tissues and it may work against a CVDs. Despite these, some other studies with antioxidants in experimental models, clinical and epidemiological studies as well as human studies strongly suggest that antioxidants might be helpful in treating diabetes and its cardiovascular complications. In future, studies may be focused on the mechanisms of oxidative stress in DM and also on the development of antioxidant therapy for the prevention of DM associated severe complications. Interesting finding is that the test drug PQQ was found to possess a better antioxidative and ameliorative potential than Vit. $\mathrm{C}$ which has also been known to act as antioxidant. ${ }^{62-67}$ The findings of this study thus provide a substantial basis for future studies aimed at assessing new PQQ based therapies for the treatment of diabetes associated CVDs, although the detailed molecular mechanism underlying the effects are currently unknown and required further intensive investigations.

\section{Acknowledgements}

Financial support from the Council of Scientific and Industrial Research, New Delhi, India (Ref. No. 09/301/(0121)/2011-EMR I) for a Senior Research Fellowship to Narendra Kumar is gratefully acknowledged.

\section{Conflict of interest}

Authors do not have any conflict of interest.

\section{References}

1. Kumar A, Khan SA, Parvez A, et al. The prevalence of hyperhomocysteinemia and its correlation with conventional risk factors in young patients with myocardial infarction in a tertiary care centre of India. Biomed Res. 2011;22:225-229.

2. Saleem TS, Chetty M, Kavimani S. Sesame oil enhances endogenous antioxidants in ischemic myocardium of rat. Rev Bras Farmacogn. 2012;22(3):669-675.

3. Haidara MA, Yassin HZ, Rateb M, et al. Role of oxidative stress in development of cardiovascular complications in diabetes mellitus. Curr Vasc Pharmacol. 2006;4(3):215-227.

4. Ivanović-Matić S, Mihailović M, Dinić S, et al. The absence of cardiomyopathy is accompanied by increased activities of CAT, Mn SOD and GST in long-term diabetes in rats. J Physiol Sci. 2010;60(4):259266.

5. Allen DA, Harwood S, Varagunam M, et al. High glucose-induced oxidative stress causes apoptosis in proximal tubular epithelial cells and is mediated by multiple caspases. FASEB J. 2003;17(8):908-910.

6. Saleem TS, Lokanath N, Prasanthi A, et al. Aqueous extract of Saussurea lappa root ameliorate oxidative myocardial injury induced by isoproterenol in rats. J Adv Pharm Technol Res. 2013;4(2):94-100.

7. Ameyama M, Matsushita K, Ohno Y, et al. Existence of a novel prosthetic group PQQ, in membrane-bound, electron transport chainlinked, primary dehydrogenases of oxidative bacteria. FEBS Lett. 1981;130(2):179-183.

8. Smidt CR, Steinberg FM, Rucker RB. Physiologic importance of pyrroloquinoline quinine. Proc Soc Exp Biol Med. 1991;197(1):19-26.

9. Misra HS, Khairnar NP, Barik A, et al. Pyrroloquinoline-quinone:a reactive oxygen species scavenger in bacteria. FEBS Lett. 2004;578(12):26-30.

10. Misra HS, Rajpurohit YS, Khairnar NP. Pyrroloquinoline-quinone and its versatile roles in biological processes. J Biosci. 2012;37(2):313-325. 
11. Zhu BQ, Simonis U, Cecchini G, et al. Comparison of pyrroloquinoline quinone and/or metoprolol on myocardial infarct size and mitochondrial damage in a rat model of ischemia/reperfusion injury. $J$ Cardiovasc Pharmacol Ther. 2006;11(2):119-128.

12. Hasani-Ranjbar S, Larijani B, Abdollahi M. A systematic review of the potential herbal sources of future drugs effective in oxidant-related diseases. Inflamm Allergy Drug Targets. 2009;8(1):2-10.

13. Lenzen $\mathrm{S}$. The mechanisms of alloxan-and streptozotocin-induced diabetes. Diabetologia. 2008;51(2):216-226.

14. Li XL, Xu G, Chen T, et al. Phycocyanin protects INS-1E pancreatic beta cells against human islet amyloid polypeptide-induced apoptosis through attenuating oxidative stress and modulating JNK and p38 mitogen-activated protein kinase pathways. Int J Biochem Cell Biol. 2009;41(7):1526-1535.

15. Takada M, Sumi M, Maeda A, et al. Pyrroloquinoline quinone, a novel protein tyrosine phosphatase $1 \mathrm{~B}$ inhibitor, activates insulin signaling in $\mathrm{C}_{2} \mathrm{C}_{12}$ myotubes and improves impaired glucose tolerance in diabetic KK-Ay mice. Biochem Biophys Res Commun. 2012;428(2):315-320.

16. Greń A. Effects of vitamin E, C and D supplementation on inflammation and oxidative stress in streptozotocin-induced diabetic mice. Int J Vitam Nutr Res. 2013;83(3):168-175.

17. Ohkawa H, Ohishi N, Yagi K. Assay of lipid peroxides in animal tissues by thiobarbituric acid reaction. Anal Biochem. 1979;95(2):351-358.

18. Griffiths G, Leverentz M, Silkowski H, et al. Lipid hydroperoxide levels in plant tissues. J Exp Bot. 2000;51(349):1363-1370.

19. Marklund S, Marklund G. Involvement of superoxide anion radical in the autoxidation of pyrogallol: A convenient assay for superoxide dismutase. Eur J Biochem. 1974;47(3):469-474.

20. Aebi HE. Catalase. In: Bergmeyer HU, editor. Methods in Enzymatic Analysis. New York: Academic Press; 1983. p. 276-286.

21. Mohandas J, Marshall JJ, Duggin GG, et al. Differential distribution of glutathione and glutathione related enzymes in rabbit kidney:possible interactions in analgesic neuropathy. Biochem Pharmocol. 1984;33(11):1801-1807.

22. Ellman GL. Tissue sulfhydryl groups. Arch Biochem Biophys 1959;82(1):70-77.

23. Lowry OH, Rosebrough NJ, Farr AL, et al. Protein measurement with the Folin phenol reagent. $J$ Biol Chem. 1951;193(1):265-275.

24. Friedwald WT, Levy RI, Fredrickson DC. Estimation of the concentration of low density lipoprotein cholesterol in plasma without use of the preparative ultracentrifuge. Clin Chem. 1972;18(6):499-502.

25. Chockalingam A, Chalmers J, Lisheng L, et al. Prevention of cardiovascular diseases in developing countries:agenda for action (statement from a WHO-ISH Meeting in Beijing, October 1999). J Hypertens. 2000;18(12):1705-1708.

26. Deepa PR, Varlakshmi P. Protective effects of certoparin sodium, a low molecular weight heparin derivative, in experimental atherosclerosis. Clin Chim Acta. 2004;339(1-2):105-115.

27. Xiong XH, Zhao Y, Ge X, et al. Production and radioprotective effects of pyrroloquinoline quinone. Int J Mol Sci. 2011;12(12):8913-8923.

28. Aruoma OI. Free radicals, oxidative stress, and antioxidants in human health and disease. J Am Oil Chem Soc. 1998;75(2):199-212.

29. Arulselvan P, Subramanian SP. Beneficial effects of Murraya koenigii leaves on antioxidant defense system and ultrastructural changes of pancreatic $\beta$-cells in experimental diabetes in rats. Chem Biol Interact. 2007;165(2):155-164.
30. Jin L, Xue HY, Jin LJ, et al. Antioxidant and pancreas protective effect of aucubin on rats with streptozotocin-induced diabetes. Eur J Pharmacol. 2008;582(1-3):162-167.

31. Liao YT, Chen CJ, Li WF, et al. Elevated lactate dehydrogenase activity and increased cardiovascular mortality in the arsenic-endemic areas of southwestern Taiwan. Toxicol Appl Pharmacol. 2012;262(3):232-237.

32. Ramachandran B, kandaswamy M, Narayanan V, et al. Insulin mimetic effects of macrocyclic binuclear oxovanadium complexes on streptozotocin-induced experimental diabetes in rats. Diabetes Obes Metab. $2003 ; 5(6): 455-461$

33. Ainscow EK, Zhao C, Rutter GA. Acute overexpression of lactate dehydrogenase-A perturbs beta-cell mitochondrial metabolism and insulin secretion. Diabetes. 2000;49(7):1149-1155.

34. Narendhirakannan RT, Subramanian S, Kandaswamy M. Biochemical evaluation of antidiabetogenic properties of some commonly used Indian plants on Streptozotocin-induced diabetes in experimental rats. Clin Exper Pharmacol Physiol. 2006;33(12):1150-1157.

35. Abdelmonem Elbassuoni E. Incretin attenuates diabetes-induced damage in rat cardiac tissue. J Physiol Sci. 2014;64(5):357-364.

36. Selvakumar E, Prahalathan C, Sudharsan PT, et al. Chemoprotective effect of lipoic acid against cyclophosphamide-induced changes in the rat sperm. Toxicology. 2006;217(1):71-78.

37. Aizenman E, Hartnett KA, Zhong C, et al. Interaction of the putative essential nutrient pyrroloquinoline quinone with the N-methyl-D-aspartate receptor redox modulatory site. J Neurosci. 1992;12(6):2362-2369.

38. Fujii J, Iuchi Y, Matsuki S, et al. Cooperative function of antioxidant and redox systems against oxidative stress in male reproductive tissues. Asian J Androl. 2003;5(3):231-242.

39. McLennan SV, Heffernan S, Wright L, et al. Changes in hepatic glutathione metabolism in diabetes. Diabetes. 1991;40(3):344-348.

40. Strain JJ. Disturbances of micronutrient and antioxidant status in diabetes. Proc Nutr Soc. 1991;50(3):591-604.

41. Sen CK, Atalay M, Hänninen O. Exercise-induced oxidative stress:glutathione supplementation and deficiency. $J$ Appl Physiol. 1994;77(5):2177-2187.

42. Parinita K, Vishnu madhuri K, Sreekanth Varma V. Study of serum lipid profile in individuals residing in and around Nalgonda. Int J pharm Bio Sci. 2012;2(1):110-116.

43. Shen GX. Lipid Disorders in Diabetes Mellitus and Current Management. Curr Pharmaceut Analys. 2007;3(1):17-24.

44. Lichtennstein AH, Appel LJ, Brands M, et al. Diet and lifestyle recommendations revision 2006. a scientific statement from the American Heart Association Nutrition Committee. Circulation. 2006;114(1):8296.

45. Acuff R V, Cai DJ, Dong ZP, et al. The lipid lowering effect of plant sterol ester capsules in hypercholesterolemic subjects. Lipids Health Dis. 2007;6:11.

46. Rajalingam R, Srinivasan N, Govindarajulu P. Effects of alloxan induced diabetes on lipid profiles in renal cortex and medulla of mature albino rats. Ind J Exp Biol. 1993;31:577-579.

47. Abbate SL, Brunzell JD. Pathophysiology of hyperlipidemia in diabetes mellitus. J Cardiovasc Pharmacol. 1990;16 Supp19:S1-7.

48. Lodovici M, Bigagli E, Bardini G, et al. Lipoperoxidation and antioxidant capacity in patients with poorly controlled type 2 diabetes. Toxicol Ind Health. 2009;25(4-5):337-341. 
49. Jatwa R, Parmar HS, Panda S, et al. Amelioration of corticosteroid-induced type 2 diabetes mellitus by rosiglitazone is possibly mediated through stimulation of thyroid function and inhibition of tissue lipid peroxidation in mice. Basic Clin Pharmacol Toxicol. 2007;101(3):177-180.

50. Bauerly K, Harris C, Chowanadisai W, et al. Altering pyrroloquinoline quinone nutritional status modulates mitochondrial, lipid, and energy metabolism in rats. PLoS One. 2011;6(7):e21779.

51. Kumar N, Kar A. Pyrroloquinoline quinone ameliorates oxidative stress and lipid peroxidation in the brain of streptozotocin-induced diabetic mice. Can J Physiol Pharmacol. 2015;93(1):71-79.

52. Ahmed RG. The physiological and biochemical effects of diabetes on the balance between oxidative stress and antioxidant defense system. Med J Islamic World Acad Sci. 2005;15(1):31-42.

53. Shoukry M, Jayyab AK. Plasma HDL in non-insulin-dependent diabetes and the effect of various types of treatment. Atherosclerosis. 1983;49(3):333-338.

54. Rang HP, Dale MM, Ritter JM, et al. Pharmacology. 5th ed. India: Elsevier; 2005.

55. Brunzell JD, Davidson M, Furberg CD, et al. Lipoprotein managemen in patients with cardiometabolic risk:consensus conference report from the American Diabetes Association and the American College of Cardiology Foundation. J Am Coll Cardiol. 2008;51(15):1512-1524.

56. Pepato MT, Mori DM, Baviera AM, et al. Fruit of the jambolan tree (Eugenia jambolana Lam.) and experimental diabetes. J Ethnopharmacol. 2005;96(1-2):43-48.

57. Ikewuchi CJ, Ikewuchi CC. Alteration of Plasma Lipid Profile and Atherogenic Indices of Cholesterol Loaded Rats by Tridax Procumbens Linn: Implications for the Management of Obesity and Cardiovascular Diseases. Biokemistri. 2009;21(2):95-99.

58. Chowanadisai W, Bauerly KA, Tchaparian E, et al. Pyrroloquinoline Quinone Stimulates Mitochondrial Biogenesis through cAMP Response Element-binding Protein Phosphorylation and Increased PGC-1 $\alpha$ Expression. J Biol Chem. 2010;285(1):142-152.
59. Mootha VK, Lindgren CM, Eriksson KF, et al. PGC-1alpha-responsive genes involved in oxidative phosphorylation are coordinately downregulated in human diabetes. Nat Genet. 2003;34(3):267-273.

60. Shi Y, Liang H, Liu Y, et al. PGC-1 $\alpha$ plays a protective role against oxidative stress in skeletal muscle. The FASEB J. 2008;22:758.

61. Holness MJ, Greenwood GK, Smith ND, et al. PPAR alpha activation and increased dietary lipid oppose thyroid hormone signaling and rescue impaired glucose-stimulated insulin secretion in hyperthyroidism. Am J Physiol Endocrinol Metab. 2008;295(6):E1380-1389.

62. Garg MC, Bansal DD. Protective antioxidant effect of vitamins C and $\mathrm{E}$ in streptozotocin induced diabetic rats. Indian $J$ Exp Biol. 2000;38(2):101-104.

63. Ceriello A, Novials A, Ortega E, et al. Vitamin C further improves the protective effect of glucagon-like peptide-1 on acute hypoglycemiainduced oxidative stress, inflammation, and endothelial dysfunction in type 1 diabetes. Diabetes Care. 2013;36(12):4104-4108.

64. Ellulu MS, Rahmat A, Patimah I, et al. Effect of vitamin C on inflammation and metabolic markers in hypertensive and/or diabetic obese adults:a randomized controlled trial. Drug Des Devel Ther. 2015;9:34053412 .

65. Khodaeian M, Tabatabaei-Malazy O, Qorbani M, et al. Effect of vitamins $\mathrm{C}$ and $\mathrm{E}$ on insulin resistance in diabetes:a meta-analysis study. Eur J Clin Invest. 2015;45(11):1161-1174.

66. Kumar N, Kar A, Panda S. Pyrroloquinoline quinone ameliorates Lthyroxine-induced hyperthyroidism and associated problems in rats. Cell Biochem Funct. 2014;32(6):538-546.

67. Kumar N, Kar A. Regulation of oxidative stress and lipid peroxidation in PTU induced mice, treated with Pyrroloquinoline quinone (PQQ). IOSR-JPBS. 2013;8(5):23-31. 